\title{
Prolonging the Shelf Life of Ready-to-Serve Pizza through Modified Atmosphere Packaging: Effect on Textural and Sensory Quality
}

\author{
Preeti Singh $^{1^{*}}$, Ali Abas Wani ${ }^{1}$, Gyanendra Kumar Goyal ${ }^{2}$ \\ ${ }^{1}$ Chair of Food Packaging Technology, Technical University of Munich, Freising, Germany; ${ }^{2}$ Food Packaging Lab, Dairy Technol- \\ ogy Division, National Dairy Research Institute, Karnal (Haryana), India. \\ Email: preeti_ndri@rediffmail.com
}

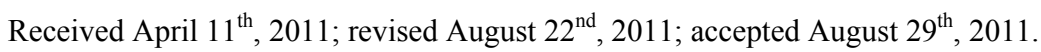

\begin{abstract}
The effects of different modified atmospheres (air: atm $1 ; 100 \% \mathrm{CO}_{2}$ : atm $2 ; 100 \% \mathrm{~N}_{2}:$ atm $3 ; 50 \% \mathrm{CO}_{2} / 50 \% \mathrm{~N}_{2}$ : atm4) on the textural and sensory characteristics of the ready-to-serve pizza at $7{ }^{\circ} \mathrm{C} \pm 1{ }^{\circ} \mathrm{C}$ were investigated. The values of hardness, gumminess and chewiness were found to be increased during the storage period while cohesiveness and springiness exhibited a decreasing trend. Overall, the $100 \% \mathrm{CO}_{2}$ product yielded the best textural and sensorial characteristics followed by $50 \% \mathrm{CO}_{2} / 50 \% \mathrm{~N}_{2}$ and $100 \% \mathrm{~N}_{2}$ when compared to conventional packed pizza at $7{ }^{\circ} \mathrm{C} \pm 1{ }^{\circ} \mathrm{C}$. Carbon dioxide caused microbial inhibition as well. The shelf life of ready-to-serve pizza significantly increased upto 45 days ( $a$ $300 \%$ increase) for the samples packaged under $100 \% \mathrm{CO}_{2}(\mathrm{~atm} 2), 50 \% \mathrm{CO}_{2} / 50 \% \mathrm{~N}_{2}(\mathrm{~atm} 4)$ and $100 \% \mathrm{~N}_{2}(\mathrm{~atm} 3)$, compared to conventional air pack (15 days).
\end{abstract}

Keywords: Modified Atmosphere Packaging, Textural Profile Analysis, Pizza, Shelf Life, Storage

\section{Introduction}

Fresh foods are increasingly preferred to frozen foods. However, spoilage is faster in the fresh state and, therefore, effective ways of slowing down deteriorative processes are needed. Modified atmosphere packaging (MAP) is extensively used to preserve a wide array of food products [1-3]. MAP is used to maintain the product's initial quality for much longer period and to extend the product's shelf life, and retains appeal to consumers. With regards to bakery products, there are many discrepancies concerning which mixture of gases is optimal $[3,4]$, since optimal MAP conditions are not universal, but system-dependent.

The textural quality is an overall physical sensation perceived about a food during mastication. The heating performance of a food system in a microwave oven is governed by oven parameters, food parameters and type of packaging [5]. There are a number of factors that render it difficult to prepare cereal-based products that can be baked, heated or reheated in a microwave oven and which will be accepted to the consumer. These have resulted in major obstacles in the development of prebaked microwaveable pizza products. The textural prop- erties of pizza are very important as the difficulties of time-temperature-moisture relations associated with the microwave heating of bakery products often culminate in the development of inferior textural product characteristics [6].

Foods usually spoil as a result of microbial activity, which causes severe changes in chemical and sensory properties, hence study was undertaken to determine the effect of selected food grade test gases on the textural and sensory characteristics of microwave-reheated pizza through objective evaluation and the interaction of the product and modified atmospheres after storage under refrigerated conditions. Acidification and $\mathrm{CO}_{2}$ production are typically ascribed to fermentative metabolism. The growth of yeasts is inhibited under highly $\mathrm{CO}_{2}$-enriched atmospheres $[3,4]$. A suitable combination of different gas mixtures (recommended for bakery products) is needed for investigation by considering the complex microbial ecology of highly heterogeneous foods, such as pizzas, where different microorganisms contribute to spoilage. This study evaluated the textural characteristics of microwave-reheated pizza using texture profile analysis (TPA) and sensorial properties during storage. The 
attributes obtained from this type of textural analysis are hardness, cohesiveness, springiness, gumminess and chewiness.

\section{Methodology}

The study was carried out at National Dairy Research Institute, Karnal, India. The methodology for this study included both qualitative and quantitative.

\subsection{Processing of Pizza}

For the preparation of mozzarella cheese from mixed milk (buffalo:cow: 60:40), the method of Alam [7] was followed. The cheddar cheese and table butter were collected from the Experimental Dairy, NDRI, Karnal, India. Pizza bases each of $20 \mathrm{~cm}$ in diameter and weighing approx. $120 \pm 10 \mathrm{~g}$ were used. The microwave oven having power output $900 \mathrm{~W}$ with internal dimensions of $36 \times$ $37 \times 23 \mathrm{~cm}^{3}$ and 32 lit capacity (Samsung, South Korea; Model Bio ceramic, CE118KF) was used for baking. The vegetables used for the preparation of pizza were first thoroughly washed and then dipped in solution of potassium metabisulphite $(2000 \mathrm{mg} / \mathrm{l})$ for $20 \mathrm{~min}$ and air-dried. The vegetables were sliced in round shape (approx. 0.5 $\mathrm{cm}$ thick) by using 'Philips' make Food Processor (Essence HR7754). The pizza samples were prepared by adapting the procedure of Alam [7] with slight modification. Firstly the lower side of each pizza base was grilled (heated) for a minute in a microwave oven on a rotating table, and then the upper side of the pizza base was smeared with approx. $5 \mathrm{~g}$ table butter followed by spreading of tomato sauce (approx. $40 \mathrm{~g}$ ) over the butter smeared pizza surface. Then green chillies and grated ginger were evenly spread all over the pizza base followed by grated mozzarella and cheddar cheese $(80: 20)$ (approx $120 \mathrm{~g} /$ pizza) concluded by vegetable toppings. The baking of pizza was done, in a preheated $\left(220^{\circ} \mathrm{C}\right)$ microwave oven, by placing on a stainless steel, elevated susceptor, at combination mode (convection at $200^{\circ} \mathrm{C}+$ microwave at $100 \%$ power level) for $7 \mathrm{~min}$. After cooling at room temperature, pizza samples were used for MAP studies at $7^{\circ} \mathrm{C} \pm 1^{\circ} \mathrm{C}$.

\subsection{Packaging}

For packaging and storage of ready-to-serve pizza, high barrier bags namely LLD/BA*/Nylon-6/BA*/LDPE $(110 \mu)$ (" poly binding agent) were used. The water vapour transmission rate (WVTR) and oxygen transmission rate (OTR) of the packaging material used were 3.96 $\mathrm{g} / \mathrm{sqm} / 24 \mathrm{~h}$ and $36 \mathrm{ml} / \mathrm{sqm} / 24 \mathrm{~h}$, respectively. The dimensions of the packages used in the study were $32.5 \times 35.0$ $\mathrm{cm}(\mathrm{L} \times \mathrm{B})$. MAP was accomplished following the method of Day [8] by using a vacuum chamber Quick
2000 machine (Alfa-Laval, Kramer, Grebe GmbH \& Co. KG Maschinenfabrik, 3560 Biedenkopf-Wallau, Germany), with gas injection after establishing a vacuum of $25^{\prime \prime} \mathrm{Hg}$ (ca.85 Pa). Packaging under atmosphere (air) was done by using vertical heat-sealing machine; model QS300 FE (Sevana Traders Ltd., Kerala, India). The prepared pizza samples were individually packed in presterilized (under UV-light for $30 \mathrm{~min}$ ) packages under different atmospheres (atm), i.e. air (atm1), $100 \% \mathrm{CO}_{2}$ $(\mathrm{atm} 2), 100 \% \mathrm{~N}_{2}(\mathrm{~atm} 3)$ and $50 \% \mathrm{CO}_{2} / 50 \% \mathrm{~N}_{2}(\mathrm{~atm} 4)$ and stored at $7{ }^{\circ} \mathrm{C} \pm 1{ }^{\circ} \mathrm{C}$. Initially the gas headspace to pizza weight ratio was approx. $1-2$ lit of gas $/ \mathrm{kg}$ of the product. The gases used were of industrial grade.

\subsection{Analytical Methods}

\subsubsection{Textural Profile Analysis (TPA)}

The stored ready-to-serve test samples were reheated in microwave oven for $2 \mathrm{~min}$ at $100 \%$ power level. To minimise variability during reheating, single samples were placed in the central position on the turntable. The reheating time was based on the amount of time necessary for the product to yield an adequately reheated appearance, i.e. $2 \mathrm{~min}$. There was a $5 \mathrm{~min}$ interval between each use of the microwave oven. After removal from the oven, the samples were left to stand for $1 \mathrm{~min}$ at room temperature and the toppings were removed. All samples were held at room temperature for $25 \mathrm{~min}$. Instrumental textural evaluation was carried out [9] using Universal Testing machine TAXT2i (Stable Micro Systems, Godalming, Surrey, UK) Texture Analyzer fitted with a $5 \mathrm{~kg}$ load cell and $75 \mathrm{~mm}$ aluminium blunt cylindrical probe (P75 mm compression platen). Based on the previous studies [9], pizza samples were cut in the round standard size cores (diameter $1.9 \mathrm{~cm}$ and height $1.1 \mathrm{~cm}$ ) by using sampler provided with the instrument, and were placed centrally beneath the probe. A crosshead speed of 5.0 $\mathrm{mm} / \mathrm{s}$ with a trigger force of $20 \mathrm{~g}$ was used to compress the cores to $80 \%$ of their original height (for two-bite profile). Each sample was compressed twice in a reciprocating motion to give a two-bite texture profile curve (Figure 1). The graphs obtained were analysed for hardness, springiness, cohesiveness, gumminess, and chewiness (Table 1) using Texture Expert Exceed Software supplied along with the instrument.

\subsubsection{Microbiological Analysis}

The pizza samples opened aseptically and prepared according to the method of Labuza and Schmidl [10] by transferring $10 \mathrm{~g}$ of sample to a stomacher bag (Seward Model, UK), containing $90 \mathrm{ml}$ of sterile Ringer's solution, and homogenised using a stomacher (Lab-Blender 400, Seward Medical, UK) for $60 \mathrm{~s}$ at room temperature 


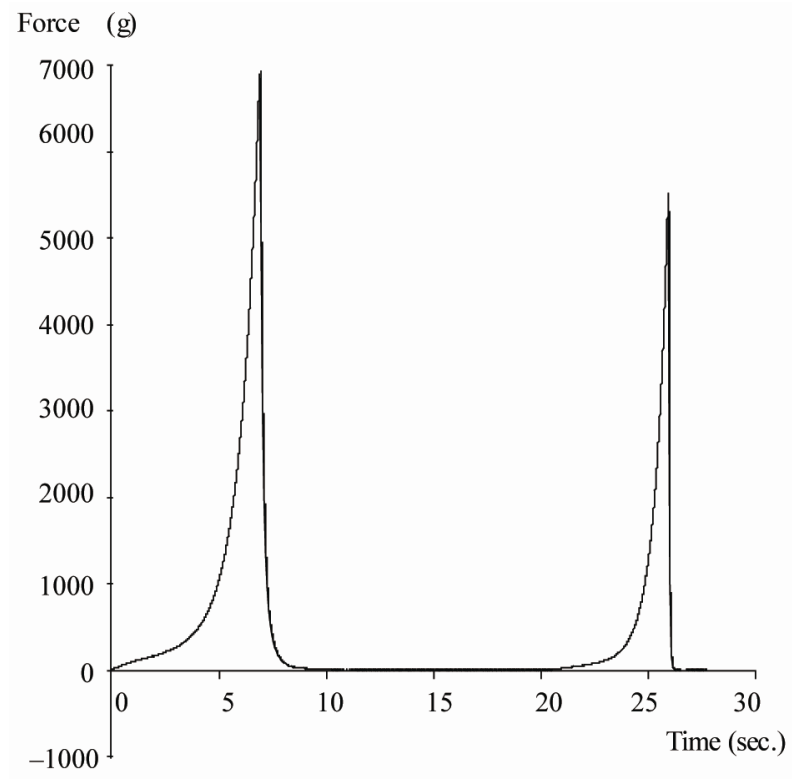

Figure 1. Typical texture profile curve of Pizza.

Table 1. Textural calculation.

\begin{tabular}{ccc}
\hline Textural variables & Definition & Unit \\
\hline Hardness & $\begin{array}{c}\text { Height of the peak during the first } \\
\text { compression }\end{array}$ & $\mathrm{g}$ \\
Cohesiveness & $\begin{array}{c}\text { Ratio of positive area under second peak } \\
\text { to that of the first peak (A2/A1) }\end{array}$ & \\
& $\begin{array}{c}\text { Distance that the sample covered during } \\
\text { the time that elapsed between the first } \\
\text { bite \& the start of second bite }\end{array}$ & $\mathrm{mm}$ \\
Springiness & $\begin{array}{c}\text { Product of hardness and cohesiveness } \\
\text { Chewiness }\end{array}$ & $\mathrm{g}$ \\
\hline
\end{tabular}

to obtain a representative sample (homogenate). Subsequently, for microbial enumeration, homogenates were serially diluted in Ringer's solution. For total plate count (TPC), the plates were prepared following the APHA methods [11]. For determining anaerobic spore formers, the method of Rao [12] was employed by using plate count agar procured from HIMEDIA, Mumbai, India. After inoculation, the surface of medium was layered with sterile agar to maintain anaerobic conditions and then incubated in anaerobic jars.

\subsection{Sensory Evaluation}

The reheated pizza samples were evaluated for sensory attributes by a trained panel for appearance, flavour, body \& texture, and overall acceptability. A quality evaluation was carried out by monitoring inflation of packages, examination for presence of yeasts and molds, and changes in the colour of pizza components. A panel of judges experienced in baked products evaluation was used for sensory analysis. Panellists were trained for a period of 3 months in 1-h sessions three times a week (36 $\mathrm{h}$ total) [13]. Triangle tests were performed in order to select seven panellists who could detect off-flavours in pizza. Prior to sample evaluation, the seven selected panellists participated in orientation sessions to familiarize with the flavour (off-odour, off-taste) and textural attributes of pizza samples. Along with the test pizza samples, fresh baked pizza was used as the reference sample. OAA as a composite of all sensory parameters (appearance, flavour, body \& texture) was evaluated using a 5point hedonic scale ranging from $1-5$, where: A score of 5 represented excellent; 4, very good; 3 , good; 2, fair; and 1, poor. A mean score of 2.5 or above indicates an acceptable product. A mean score below 2.5 marks the end of refrigerated pizza shelf life [14].

\subsection{Statistical Analysis}

Experiments were replicated twice on different occasions with different ready-to-serve pizza samples. Different packages were sampled on predetermined time intervals. Analyses were run in triplicate for each replicate $(\mathrm{n}=2 \times$ $3)$. Experimental data were subjected to analysis of variance (ANOVA). Means and standard deviations were calculated, and, when F-values were significant at the $p<$ 0.05 level, mean differences were separated by the Least Significant Difference (LSD) procedure [15].

\section{Results and Discussion}

\subsection{Textural Analysis}

Instrumental textural evaluation of fresh baked (ready-toserve) pizza samples show that the hardness ( $\mathrm{g}$ ) averaged 6621.87 , cohesiveness averaged 0.461 , springiness $(\mathrm{mm})$ averaged 0.786, gumminess (g) averaged 3000.01 and chewiness $(\mathrm{g} \times \mathrm{mm})$ averaged 2330.81 . However, Clarke and Farrell [9] reported the following values for textural characteristics of microwave-reheated pizza $\rightarrow$ hardness (g): 12571, 14461 and 19989 for samples reheated for $120 \mathrm{~s}, 150 \mathrm{~s}$ and $180 \mathrm{~s}$ respectively; cohesiveness: 0.481 for $120 \mathrm{~s}, 0.500$ for $150 \mathrm{~s}$ and 0.554 for $180 \mathrm{~s}$; springiness $(\mathrm{mm}): 0.916,0.914$ and 0.947 for samples reheated for 120,150 and $180 \mathrm{~s}$ respectively; gumminess (g): 6079,7230 and 11097 for samples reheated for 120, 150 and $180 \mathrm{~s}$ respectively; chewiness $(\mathrm{g} \times \mathrm{mm}): 5596,6604$ and 10527 for pizza samples reheated for 120,150 and $180 \mathrm{~s}$, respectively.

\subsubsection{Hardness}

The changes in hardness (the force necessary to deform 
the food between the molar teeth) of baked pizza samples packaged under 4 different atmospheres and stored at $7^{\circ} \mathrm{C}$ are illustrated in Figure 2. The initial hardness value (g) of 6621.87 increased to 16602.76 (atm1), 8606.27 (atm2), 13744.69 (atm3) and 12859.69 (atm4) after 30 days of storage revealing that the hardness was minimum for the samples packed under $100 \% \mathrm{CO}_{2}$ (atm2) followed by $50 \% \mathrm{CO}_{2} / 50 \% \mathrm{~N}_{2}$ (atm4), $100 \% \mathrm{~N}_{2}$ (atm3) and air (atm1) respectively, in ascending order. Our results pertaining to proteolysis of samples during storage also showed that the tyrosine content (data not shown) was lowest in case of baked pizza samples packed under atm2 followed by atm4, atm3 and atm1, respectively. Clarke and Farrell [9] reported the hardness values (g) for control pizza samples reheated in microwave for $120 \mathrm{~s}, 150 \mathrm{~s}$ and $180 \mathrm{~s}$ as 12571,14461 and 19989 respectively, and concluded that hardness increased with increased reheating times. In general, our results (Figure 2) are in harmony with the observations of Alam [7] who reported that at the end of 12 weeks $\left(\right.$ at $7^{\circ} \mathrm{C} \pm 1^{\circ} \mathrm{C}$ ), the hardness of mozzarella cheese was minimum for the samples packed under $100 \% \mathrm{CO}_{2}$ followed by $50 \% \mathrm{CO}_{2} / 50 \% \mathrm{~N}_{2}$, and $100 \% \mathrm{~N}_{2}$, respectively. Analysis of the data revealed that the intervals of storage, different atmospheres and the interaction of intervals and atmospheres contributed
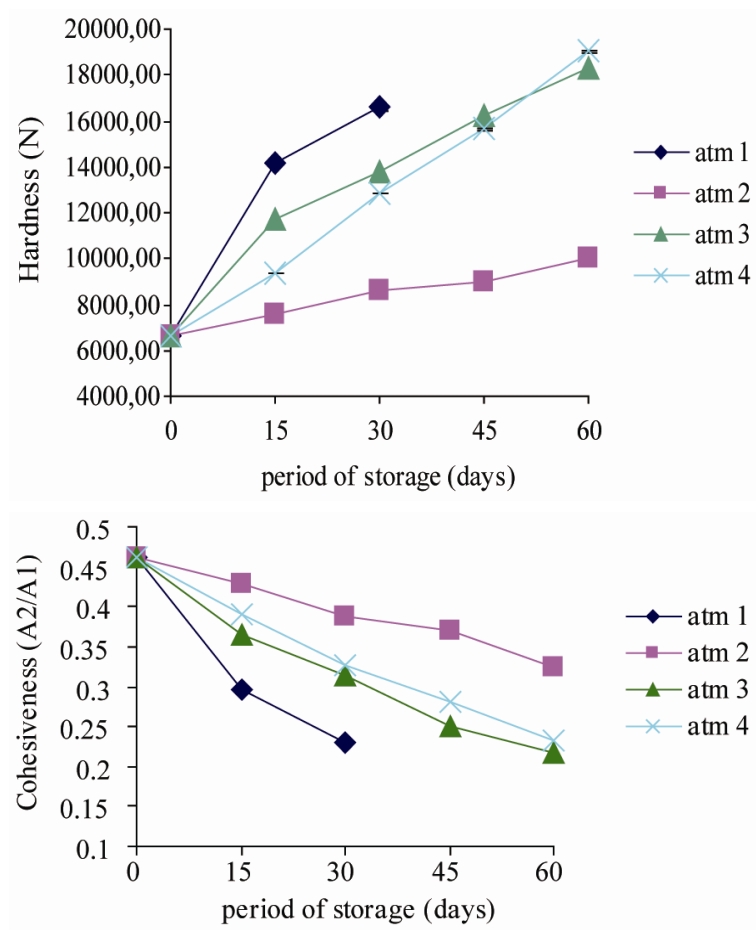

Figure 2. Textural changes in hardness and cohesiveness of chilled ready-to-serve pizza samples packaged in four different atmospheres. Each point is the mean SE (0.1 - 0.6) of two replicate experiments. significantly $(p<0.01)$ towards the changes in hardness of baked pizza samples.

\subsubsection{Cohesiveness}

Cohesiveness is molecular attraction by which the particles of the body are bonded throughout the mass. The changes in cohesiveness (A2/A1) of baked pizza samples packaged under different atmospheres and stored at $7^{\circ} \mathrm{C}$ $\pm 1{ }^{\circ} \mathrm{C}$ are presented in Figure 2. The cohesiveness of baked pizza samples showed a decreasing trend throughout the entire storage period for all the atmospheres (Figure 2). The initial cohesiveness value of $0.461 \mathrm{de}-$ creased to 0.231 (atm1), 0.388 (atm2), 0.314 (atm3) and 0.327 (atm4) respectively, after 30 days of storage revealing that the minimum decrease in cohesiveness was observed for the samples packed under atm2 $\left(100 \% \mathrm{CO}_{2}\right)$ followed by atm4 $\left(50 \% \mathrm{CO}_{2} / 50 \% \mathrm{~N}_{2}\right)$, atm3 $\left(100 \% \mathrm{~N}_{2}\right)$ and atm1 (air), in ascending order. Clarke and Farrell [9] indicated that cohesiveness values for control pizza samples increased as the time of reheating of microwave pizza increased: 0.481 for $120 \mathrm{~s}, 0.500$ for $150 \mathrm{~s}$ and 0.554 for $180 \mathrm{~s}$. ANOVA of the data showed that results were not significant $(p<0.05)$ towards the changes in cohesiveness of baked pizza samples.

\subsubsection{Springiness}

The influence of MAP on the springiness of baked pizza samples packed under 4 atmospheres at $7{ }^{\circ} \mathrm{C} \pm 1{ }^{\circ} \mathrm{C}$ is depicted in Figure 3. The initial mean springiness value $(\mathrm{mm})$ for fresh baked pizza samples was 0.786 which decreased to 0.524 for samples packed under atm1, 0.688 under atm2, 0.590 under atm 3 and 0.656 under atm 4 after 30 days, while the value decreased to 0.584 for atm2, 0.429 for atm3, and 0.563 for atm 4 after 60 days of storage indicating lowest value for air packed samples, and highest for samples packed under $100 \% \mathrm{CO}_{2}$. Perhaps higher degree of proteolysis [16] might be the reason for maximum decrease in springiness in case of samples packaged under atm1, and least proteolysis in samples packaged under atm2 (Figure 3). The results are in agreement with the findings of Alam [7] who reported more decrease in springiness for air packed mozzarella cheese samples as compared to samples packaged under $100 \% \mathrm{~N}_{2}, 50 \% \mathrm{CO}_{2} / 50 \% \mathrm{~N}_{2}$ and $100 \% \mathrm{CO}_{2}$ respectively, in ascending order. Ghosh [17] also observed that springiness of mozzarella cheese samples decreased with the increase in storage period, regardless of packing material and storage temperature. Statistically, the influence of intervals of storage and four types of atmospheres on the springiness of baked pizza samples was found to be not significant $(p<0.05)$.

\subsubsection{Gumminess}

The changes in gumminess of baked pizza samples pack- 

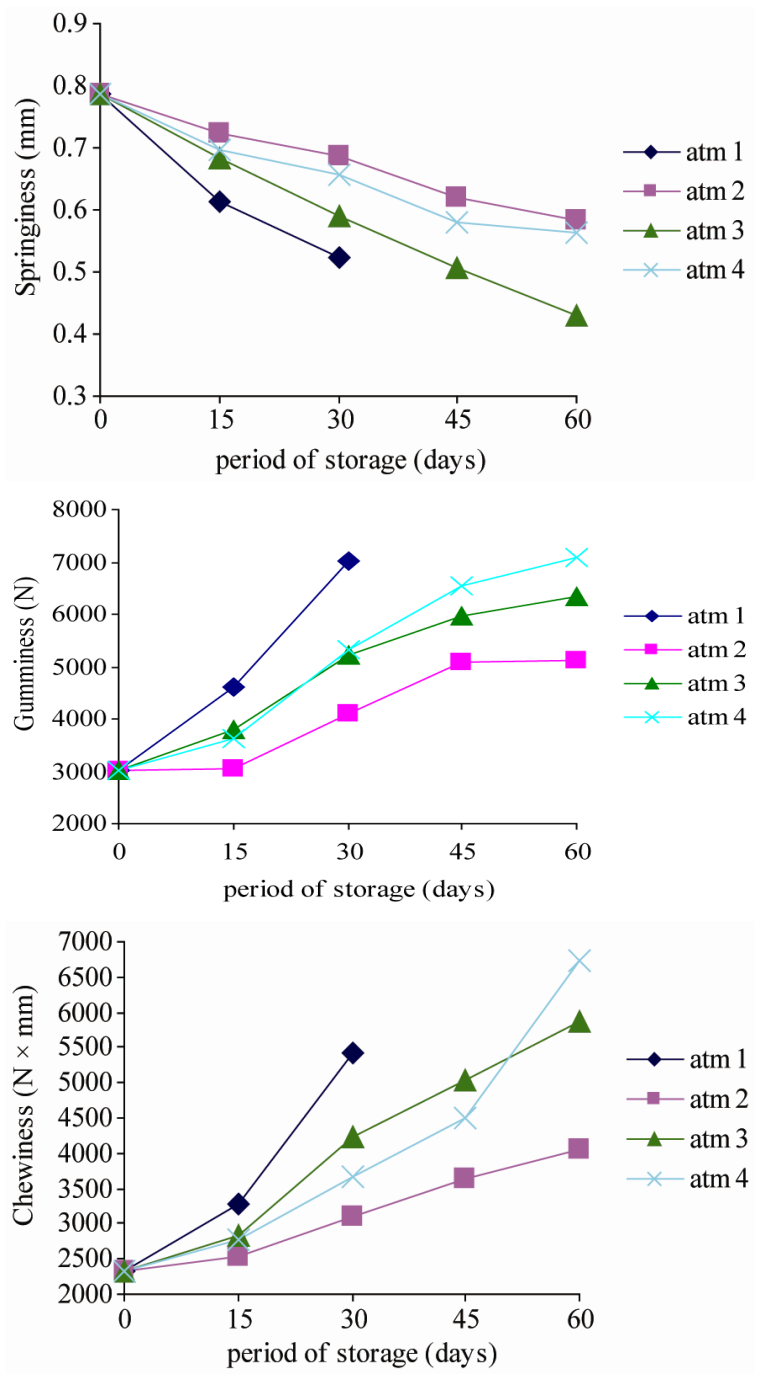

Figure 3. Textural changes in springiness, Gumminess and chewiness of chilled ready-to-serve pizza samples packaged in four different atmospheres. Each point is the mean SE $(0.1$ - 0.6) of two replicate experiments.

aged under 4 atmospheres and stored at $7^{\circ} \mathrm{C} \pm 1{ }^{\circ} \mathrm{C}$ for various time periods are presented in Figure 3. The mean initial value of gumminess (g) was found to be 3000.01 , which continued to increase in all the pizza samples. At the end of 30 days storage, the values for gumminess increased to $7016.00 \mathrm{~g}(\mathrm{~atm} 1), 4112.81 \mathrm{~g}(\mathrm{~atm} 2), 5212.13$ $\mathrm{g}(\mathrm{atm} 3)$ and $5312.74 \mathrm{~g}(\mathrm{~atm} 4)$, respectively. From these results, it can be inferred that the gumminess increased maximum for the samples packed under air followed by $50 \% \mathrm{CO}_{2} / 50 \% \mathrm{~N}_{2}, 100 \% \mathrm{~N}_{2}$ and $100 \% \mathrm{CO}_{2}$, in descending order. Clarke and Farrell [9] also reported increase in gumminess values $(\mathrm{g})$ when the control pizza samples were reheated for increased times, and the values reported by them were 6079 (120 s), 7230 (150 s) and
11097 (180 s). However, these results are at variance with the findings of Ghosh [17], Malhotra [18] and Alam [7] who reported consistent decrease in gumminess of cheese samples during storage. The analysis of variance of the data concerning gumminess of baked pizza samples indicates that the intervals of storage, the 4 types of atmospheres, and their interactions all individually, were highly significant $(p<0.01)$.

Figure 3 represents the changes in chewiness of baked pizza samples packed under 4 different atmospheres and stored at $7^{\circ} \mathrm{C} \pm 1^{\circ} \mathrm{C}$. The mean initial value of chewiness $(\mathrm{g} \times \mathrm{mm})$ was found to be 2330.81 , which increased to 3280.75 (atm1), 2526.33 (atm2), 2833.35 (atm3) and 2778.08 (atm4) respectively after 15 days of storage. This trend persisted even during further storage of 30 days. However, the minimum increase in chewiness was observed for pizza samples packed under $100 \% \mathrm{CO}_{2}$ (32.89\% increase), followed by $50 \% \quad \mathrm{CO}_{2} / 50 \% \quad \mathrm{~N}_{2}$ (56.96\% increase), $100 \% \mathrm{~N}_{2}(81.44 \%$ increase), and air (132.85\% increase) respectively. Clarke and Farrell [9] also reported increase in chewiness values when the control pizza samples were reheated for longer time. However, Ghosh [17], Malhotra [18] and Alam [7] reported decrease in chewiness values during storage of cheese samples. The analysis of variance of the data on chewiness revealed that the various time intervals of storage, the 4 types of atmospheres, and their interactions, played a very significant $(p<0.01)$ role in influencing the chewiness of the product.

\subsection{Microbiological Analysis}

The values for TPC were in the range as reported by Kamel and Manji [19]; Fasano and Gallo [20]; Donnelly [21]; CFS [22] for baked and refrigerated pizza samples (Figure 4). Initial values of TPC reached $6.68 \mathrm{cfu} / \mathrm{g}$, which is considered as the unsatisfactory limit for fresh pizza as defined by CFS [22] ca. on day $30^{\text {th }}$ of storage (air packaged samples). The atm2, atm3 and atm4 packaged samples did not reach this value throughout the 60 days of storage period under refrigeration. After 30 days, the atm2 contributed to significantly lower $(p<0.01)$ TPC count than the atm 3 and air pizza samples. This is a result of an extension of lag phase of growth, and a decrease in the growth rate during logarithmic phase [3]. The results are in agreement with the findings of Scott and Smith [23], who investigated the effect of $\mathrm{CO}_{2}, \mathrm{~N}_{2}$ and air atmospheres on the shelf life of cottage cheese and concluded that $\mathrm{CO}_{2}$ slightly decreased the bacterial count, but $\mathrm{N}_{2}$ did not significantly decrease the count. The results also confirm the earlier findings of Alves et al. [24]; Fedio et al. [25]; Eliot et al. [26]; Alam [7], who while working on MAP of mozzarella cheese observed 
that $\mathrm{CO}_{2}$ had bactericidal effect. The counts of anaerobic spore formers were also low $(<3 \log \mathrm{cfu} / \mathrm{g})$ and show increasing trend in all pizza samples with anaerobic conditions and slight decrease in air packed samples throughout the entire storage period (Figure 4). Nissen et al. [27] stored vacuum packed Salmon, Herb sauce and Chicken, at $20^{\circ} \mathrm{C}$, and observed that the initial anaerobic count of $<100$ in all the three products increased respectively to $6.2 \times 10^{6}, 3.7 \times 10^{6}$ and $1.7 \times 10^{7}$. Farber [3] indicated that at atmospheric pressure, $100 \% \mathrm{CO}_{2}$ could delay toxin production by Clostridium sp. when compared with $100 \% \mathrm{~N}_{2}$ levels. However, Smoot and Pierson [28] reported that $\mathrm{CO}_{2}$ had little effect on germination and toxigenesis of spore formers such as Clostridium botulinum.

\subsection{Sensory Analysis}

The results of the sensory evaluation (appearance, flavour and body $\&$ texture) of the reheated pizza samples are presented as overall acceptability (OAA) scores (Figure 5). Combined scores for appearance, flavour and body \& texture showed a similar pattern of decreasing acceptability (individual results not shown). The OAA of reheated pizza samples exhibited a decreasing trend throughout the storage period under all studied atmospheres. The initial OAA score 4.7 (atm1) decreased to
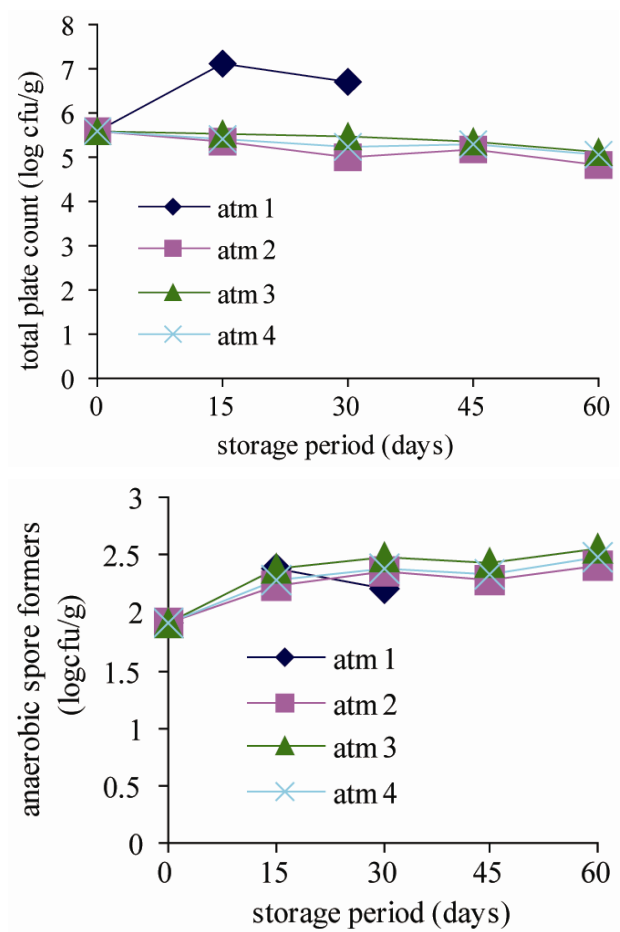

Figure 4. Changes (log cfu/g) in total plate count and anaerobic spore formers of chilled ready-to-serve pizza samples. Each point is the mean SE (0.1 - 0.4).

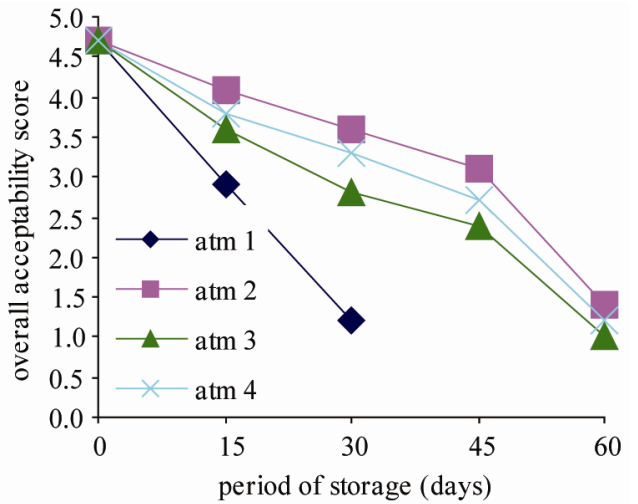

Figure 5. Changes in OAA scores of chilled ready-to-serve pizza samples packaged in different atmospheres.

2.9 and 1.2 respectively, after 15 and 30 days, indicating that the air packed baked pizza samples were acceptable only upto 15 days. At the end of 60 days, none of the sample was acceptable under all the 3 modified atmospheres (atm2, atm3, atm4), but were acceptable only upto 45 days. The samples packed under $100 \% \mathrm{CO}_{2}$ (atm2) were liked most followed by $50 \% \mathrm{CO}_{2} / 50 \% \mathrm{~N}_{2}$ and $100 \%$ $\mathrm{N}_{2}$ respectively, in descending order (Figure 5). All pizza samples received higher scores during the first 15 days, while after this period significant differences $(p$ $<0.01$ ) were observed in sensory scores between air and MA packed samples. The limit of OAA (score 2.5) was reached somewhat around day 15 (air samples) and day 45 (atm3 samples), while atm2 and atm4 samples never reached this limit within 45 days of the experiment (Figure 5). OAA (Figure 5) of air and MA-packaged pizza samples correlated rather well with TPC data (Figure 4). In general, the results are in agreement with the findings of Maniar et al. [29] and Alves et al. [24] who also observed that $100 \% \mathrm{CO}_{2}$ atmosphere best maintained the sensorial characteristics of the product. Baked pizza samples were better preserved under atm2 and atm4 maintaining acceptable odour/taste attributes even on final day of storage

The values of hardness, gumminess and chewiness were found to be increased during the storage period while cohesiveness and springiness exhibited a decreasing trend. The shelf life of MAP baked (ready-to-serve) pizza was determined by subjecting the samples to different atmospheres (air, $100 \% \mathrm{CO}_{2}, 100 \% \mathrm{~N}_{2}$, and $50 \%$ $\mathrm{CO}_{2} / 50 \% \mathrm{~N}_{2}$ ) stored at various time intervals at $7^{\circ} \mathrm{C} \pm$ $1{ }^{\circ} \mathrm{C}$. The results for the overall acceptability were used to establish the product's shelf life. The shelf life of readyto-serve (baked) pizza significantly increased upto 45 days (a 300\% increase) for the samples packaged under $100 \% \mathrm{CO}_{2}(\mathrm{~atm} 2), 50 \% \mathrm{CO}_{2} / 50 \% \mathrm{~N}_{2}$ (atm 4) and $100 \%$ 
$\mathrm{N}_{2}$ (atm 3), compared to conventional air pack (15 days) due to the preservative effect of $\mathrm{CO}_{2}$ on total plate count (especially lactobacilli and yeasts) as well as other quality characteristics of pizza.

\section{REFERENCES}

[1] I. J. Church and A. L. Parson, "Modified Atmosphere Packaging Technology: A Review," Journal of the Science of Food and Agriculture, Vol. 67, No. 3, 1995, pp. 143-152. doi:10.1002/jsfa.2740670202

[2] C. A. Phillips, "Modified Atmosphere Packaging and Its Effects on the Microbiological Quality and Safety of Produce," International Journal of Food Science and Technology, Vol. 31, No. 4, 1996, pp. 463-479. doi:10.1046/j.1365-2621.1996.00369.x

[3] J. M. Farber, "Microbiological Aspects of Modified Atmosphere-Packaging Technology: A Review," Journal of Food Protection, Vol. 54, No. 4, 1996, pp. 58-70.

[4] R. Ahvenainen, E. Skyttae and R. L. Kivikataja, "The Influence of Modified Atmosphere Packaging on the Quality of Selected Ready-to-Eat Foods," LWT, Vol. 23, No. 1, 1990, pp. 139-147.

[5] R. F. Schiffmann, "Problems in Standardizing Microwave Oven Performance," Microwave World, Vol. 11, No. 2, 1990, pp. 20-24.

[6] R. F. Schiffmann, "Understanding Microwave Reactions and Interactions," Food Product Design, Vol. 4, 1993, pp. 72-88.

[7] T. Alam, "Studies on the Modified Atmosphere Packaging of Mozzarella Cheese," Ph.D. Dissertation, NDRI, Karnal, India, 2004.

[8] B. P. F. Day, "Guidelines for the Good Manufacturing and Handling of Modified Atmosphere Packed Food Products," The Campden Food and Drink Research Association, Chipping Campden, U.K. Technical Manual No. 34, 1992.

[9] C. I. Clarke and G. M. Farrell, "The Effects of Recipe Formulation on the Textural Characteristics of Microwave-Reheated Pizza Bases," Journal of the Science of Food and Agriculture, Vol. 80, No. 8, 2000, pp. 12371244.

doi:10.1002/1097-0010(200006)80:8<1237::AID-JSFA63 $0>3.0 . \mathrm{CO} ; 2-8$

[10] T. P. Labuza and M. K. Schmidl, "Accelerated Shelf Life Testing of Foods," Food Technology, Vol. 9, No. 2, 1985, pp. 57-62, 64, 134.

[11] APHA, "Standard Methods for the Examination of Dairy Products," 15th Edition, American Public Health Association, Washington, DC, 1985.

[12] K. V. S. S. Rao, “A Process for Manufacture of Paneer Like Product,” Ph.D. Dissertation, NDRI, Karnal, India, 1991.

[13] R. J. Winger and C. G. Pope, "Selection and Training of Panellists for Sensory Evaluation of Meat Flavors," Journal of Technology, Vol. 16, No. 4, 1976, pp. 661-669.
[14] M. L. Cabo, L. Pastoriza, M. Bernardez and J. J. R. Herrera, "Effectiveness of $\mathrm{CO}_{2}$ and Nisaplin on Increasing Shelf Life of Fresh Pizza," Food Microbiology, Vol. 18, No. 3, 2001, pp. 489-498. doi:10.1006/fmic.2001.0424

[15] R. G. D. Steel and J. H. Torrie, "Principles and Procedures of Statistics-A Biometric Approach," Mc GrawHill, New York, 1980, p. 22.

[16] R. C. Lawrence, L. K. Creamer and J. Gilles, "Texture Development during Cheese Ripening," Journal of Dairy Science, Vol. 70, No. 3, 1987, pp. 1748-1760. doi:10.3168/jds.S0022-0302(87)80207-2

[17] B. C. Ghosh, "Production, Packaging and Preservation of Mozzarella Cheese from Buffalo Milk Using Microbial rennet," Ph.D. Dissertation, Kurukshetra University, Kurukshetra, India, 1987.

[18] G. H. Malhotra, "Accelerated Ripening of Gouda Cheese Manufactured from Buffalo Milk Using Cheese Manufactured from Buffalo Milk Using Microbial Rennet," Ph.D. Dissertation, NDRI, Karnal, India, 1991.

[19] B. Kamel and B. Manji, "Effect of Frozen Storage on Different Pizza Formulations," Cereal Foods World, Vol. 31, No. 3, 1986, pp. 751-755.

[20] L. Fasano and C. Gallo, "Pizza-Bases with Tomato Packaged with Modified Atmosphere: Environment Monitoring and Shelf Life Studies," Industrie Alimentari, Vol. 11, No. 3, 2001, pp. 1039-1044.

[21] C. W. Donnelly, "Detection and Isolation of Listeria monocytogenes from Food Samples: Implications of sublethal Injury," Journal of AOAC International, Vol. 85, No. 3, 2002, pp. 495-500.

[22] Centre for Food Safety, "Microbiological Guidelines for Ready-to-Eat Foods," Risk Assessment Section, Centre for Food Safety, Food and Environmental Hygiene Department, Hongkong, 2007, pp. 1-15.

[23] C. R. Scott and H. O. Smith, "Cottage Cheese Shelf Life and Special Gas Atmospheres," Journal of Food Science, Vol. 36, No. 3, 1971, pp. 78-80. doi:10.1111/j.1365-2621.1971.tb02038.x

[24] M. V. R. Alves, C. I. G. D. L. Sarantopoulos, A. G. F. van Dender and J. D. A. F. Faria, "Stability of Sliced Mozzarella Cheese in Modified Atmosphere Packaging," Journal of Food Protection, Vol. 59, No. 3, 1996, pp. 838-844.

[25] W. M. Fedio, A. Macleod and L. Ozimek, "The Effect of Modified Atmosphere Packaging on the Growth of Microorganisms in Cottage Cheese," Milchwissenschaft, Vol. 49, No. 2, 1994, pp. 622-629.

[26] S. C. Eliot, J. C. Vuillemard and J. P. Emond, "Stability of Shredded Mozzarella Cheese under Modified Atmosphere Packaging," Journal of Food Science, Vol. 63, No. 2, 1998, pp. 1075-1080.

[27] H. Nissen, J. T. Rosnes, J. Brendehaug and G. H. Kleiberg, "Safety Evaluation of Sous Vide-Processed Ready Meals," Letters in Applied Microbiology, Vol. 35, No. 3, 2002, pp. 433-438. 
doi:10.1046/j.1472-765X.2002.01218.x

[28] L. A. Smoot and M. D. Pierson, "Inhibition and Control of Bacterial Spore Germination," Journal of Food Protection, Vol. 45, No. 3, 1982, pp. 84-92.
[29] B. Maniar, A. J. E. Marcy, J. R. Bishop and S. E. Duncan, "Modified Atmosphere Packaging to Maintain Direct Set Cottage Cheese Quality," Journal of Food Science, Vol. 59, No. 3, 1994, pp. 1305-1308, 1327. doi:10.1111/j.1365-2621.1994.tb14701.x 